\section{Estudo cobebate}

em Testão Plamejamento
Revista Estudo \& Debate, Lajeado, v. 27, n. 1, 2020. ISSN 1983-036X DOI: http://dx.doi.org/10.22410/issn.1983-036X.v27i1a2020.2427

\title{
ESTUDO COMPARATIVO DA TRANSPARÊNCIA NOS PORTAIS ELETRÔNICOS DE MUNICÍPIOS GAÚCHOS
}

\author{
Laura Luiza Mallmann Franke, Monize Sâmara Visentini², Micheli Dos Santos ${ }^{3}$, \\ Ari Söthe ${ }^{4}$
}

\begin{abstract}
Resumo: A incorporação de novas ferramentas tecnológicas aliadas às leis de acesso à informação gerou uma facilidade maior na comunicação entre governo e sociedade no que se refere à participaçáo dos cidadáos em assuntos públicos e nos processos de tomada de decisōes políticas (LACERDA, 2016). Este trabalho teve como objetivo avaliar, para o ano de 2018, através da Escala Brasil Transparente (EBT), o nível de transparência nos portais eletrônicos das 25 prefeituras que fazem parte do Conselho Regional de Desenvolvimento das Missóes/ RS (COREDE Missões), bem como comparar este ranqueamento com pesquisas anteriores. A metodologia utilizada foi a Escala Brasil Transparente (EBT), elaborada pela Controladoria Geral da União (CGU). O período de coleta de dados foi de junho de 2018 até julho de 2018, tendo como amostra os 25 municípios que integram o COREDE Missōes. Os dados foram analisados descritivamente com auxílio do software Microsoft Excel 2016, versão 2001. Os resultados indicam que houve melhora na nota da transparência do portal eletrônico em 52\% dos municípios investigados entre os anos de 2016 e 2018. Entretanto, parcela dos municípios investigados pode ser considerada pouco transparente na forma passiva, pois muitos portais ainda não estão estruturados para receber solicitaçôes dos cidadãos. Essa pesquisa permite que os gestores públicos identifiquem as principais dificuldades da relação entre cidadão/administração pública no que diz respeito à participação popular na sua gestão, principalmente em relação aos portais eletrônicos.
\end{abstract}

Palavras-chave: Lei de Acesso à Informação. Administração Pública.. Transparência municipal.

1 Mestranda do Programa de Pós-Graduação em Desenvolvimento e Políticas Públicas - Universidade Federal da Fronteira Sul (UFFS). Graduada em Administração (UFFS) - Cerro Largo, RS. E-mail: lauraluizafranke@ gmail.com.

2 Doutora em Administraçáo pela Universidade Federal do Rio Grande do Sul. Professora do Curso de Graduação em Administração da Universidade Federal da Fronteira Sul - Campus Cerro Largo. Professora Titular do Programa de Pós-Graduação em Desenvolvimento e Políticas Públicas da Universidade Federal da Fronteira Sul - Campus Cerro Largo. Email: monize.visentini@uffs.edu.br.

3 Mestre em Desenvolvimento e Políticas Públicas - Universidade Federal da Fronteira Sul (UFFS). Graduada em Administração pela Universidade Regional Integrada do Alto Uruguai e das Missōes (2007) e especialista em Administração Estratégica pela UNIASSELVI. E-mail: micheli.santos@uffs.edu.br.

4 Graduado em Ciências Contábeis e especialização em Administração pela Universidade Sáo Francisco (USF). Mestrado em Ciências Contábeis pela Universidade Regional de Blumenau (FURB). Doutorado em Desenvolvimento Regional pela Universidade Regional de Blumenau (FURB). Professor da Universidade Federal Fronteira Sul (UFFS) - Cerro Largo, RS. E-mail: ari.sothe@uffs.edu.br. 


\title{
COMPARATIVE STUDY OF TRANSPARENCY IN THE WEBSITES OF GAÚCHOS MUNICIPALITIES
}

\begin{abstract}
The incorporation of new technological tools combined with access to information laws has made it easier for the government and society to communicate with regard to citizen participation in public affairs and political decision-making processes (LACERDA, 2016). This article evaluates for the year of 2018, by Escala Brasil Transparente (EBT, Brazilian transparency scale), the transparency level of 25 municipalities websites that are part of the Conselho Regional de Desenvolvimento das Missóes/RS (COREDE Missóes), as well compares this ranking with previous research. The methodology used was the Brazil Transparent Scale (EBT), prepared by the Comptroller General of the Union (CGU). The data collection period was from June 2018 to July 2018, having as sample the 25 municipalities that make up the COREDE Missóes. The data were analyzed descriptively with Microsoft Excel 2016 software. The results indicate that there was an improvement in the website's transparency in 52\% of the municipalities investigated between 2016 and 2018. However, a portion of the municipalities investigated can be considered as non-transparent in the passive form, since many websites are not yet structured to receive requests from citizens. This research allows the public managers to identify the main difficulties in the relationship between citizen / public administration concerning popular participation in their management, especially in relation to electronic portals.
\end{abstract}

Keywords: Freedom of Information Act. Public Administration. Municipal Transparency.

\section{Introdução}

Um dos temas mais abordados atualmente quando se trata da Administração Pública é a transparência. Pires (2013) revela que o interesse sobre esse tema aumentou significativamente conforme o passar dos anos devido aos dispositivos legais que surgiram. Tais dispositivos dão o direito ao cidadão de acessar informaçóes em níveis nacional, estadual e municipal, obrigando, dessa forma, os entes públicos a divulgarem relatórios periódicos sobre as aplicações dos recursos públicos.

O dispositivo legal relacionado diretamente com a transparência das informaçóes públicas é a Lei de Acesso à Informação (LAI), que foi regulamentada em 18 de novembro de 2011 e entrou em vigor em 2012, apesar do direito ao acesso à informação estar previsto na Constituição Federal de 1988 (BRASIL, 1988). "O cumprimento da LAI depende, principalmente, de um efetivo comprometimento com a transparência pública [...]" (MICHENER; MONCAU; VELASCO, 2015, p. 16). Os autores afirmam ainda que as autoridades dos órgãos públicos brasileiros têm o dever de cumprir com a LAI para oferecer à população uma maior eficiência na gestão pública, maior controle dos gastos e políticas públicas, fazendo com que esses benefícios se espalhem por todas as instâncias do poder público.

Alguns instrumentos foram desenvolvidos para medir a transparência pública nos estados e municípios brasileiros e, entre eles, a Escala Brasil Transparente (EBT), desenvolvida pela Controladoria Geral da União (CGU, 2016). Apesar de ser uma metodologia recente, a CGU já realizou três rodadas da Escala Brasil Transparente: EBT 1.0, EBT 2.0 e EBT 3.0, sendo as duas primeiras divulgadas em maio e novembro de 2015 e a terceira no ano de 2016. Para verificar a transparência dos municípios, a escala se divide em 12 quesitos abrangentes dos temas "Regulamentação da LAI" e "Transparência Passiva". 
A partir da importância da LAI e da transparência das informações públicas, o objetivo deste trabalho é avaliar, para o ano de 2018, através EBT, o nível de transparência nos portais eletrônicos das prefeituras que fazem parte do Conselho Regional de Desenvolvimento das Missóes/RS (COREDE Missóes), bem como comparar este ranqueamento com a última análise da EBT versão 3.0, realizada pela Controladoria Geral da União (CGU, 2016), e com o estudo de Santos (2017).

Os Conselhos Regionais de Desenvolvimento (COREDES) tiveram início a partir do ano de 1991, instituídos pela Lei $\mathrm{n}^{\circ} 10.283$, de 17 de outubro de 1994, com os objetivos de: promover o desenvolvimento regional de forma harmônica e sustentável; integrar os recursos e açóes do Governo e da regiáo; melhorar a qualidade de vida da populaçáo; distribuir de forma igual a riqueza produzida; estimular a permanência dos cidadáos em suas respectivas regióes; e preservar e recuperar o meio ambiente (COELHO; FRIZZO; MARCONDES, 2010). Atualmente são 28 COREDES, os quais se articulam em nove regióes funcionais, sendo o COREDE Missóes, objeto de estudo deste trabalho, parte da região funcional 7, localizado na regiáo noroeste do Rio Grande do Sul (RS) e composto por 25 municípios (BÜTTENBENDER; SIEDENBERG; ALLENBRANDT, 2011).

Santos (2017) investigou a regulamentação da LAI por meio da EBT nos municípios do COREDE Missóes. Este estudo indicou que apenas 28\% dos municípios integrantes desse COREDE regulamentam a LAI por instrumento legal e 36\% dos municípios são transparentes na forma passiva. Isso indica a importância de se investigar o COREDE Missões, tendo em vista que ainda poucos municípios estão regulamentando esta lei e também pelo fato de o COREDE possuir importância regional. Levando em consideraçáo que o período de realização do estudo de Santos (2017) era de transiçáo na gestáo pública municipal - devido as eleiçôes no ano de 2016 -, neste estudo busca-se verificar se, com o ingresso e consolidação das atuais gestóes, houve mudanças no quadro da transparência pública divulgada nos portais das prefeituras.

Além disso, espera-se que esta pesquisa proporcione aos munícipes do COREDE Missóes maiores informaçóes sobre a gestáo da informaçáo atual de seus municípios. Assim terão "[...] maior quantidade e melhor qualidade informacional [...]" (JACQUES; QUINTANA; MACAGNAM, 2013 p. 3), além de contribuir para uma reflexão sobre essas informaçôes que lhes são disponibilizadas (SANTOS, 2017).

\section{$2 \mathrm{O}$ uso das tecnologias de informaçáo e comunicação a favor da transparência pública}

Os debates a respeito da transparência no governo começaram a ocorrer nas últimas décadas, fazendo com que muitos países aprovassem leis de acesso à informação pública (ANGÉLICO, 2012). A incorporação de novas ferramentas tecnológicas aliadas às leis de acesso à informação gerou uma facilidade maior na comunicação entre governo e sociedade no que se refere à participação dos cidadãos em assuntos públicos e nos processos de tomada de decisōes políticas (LACERDA, 2016). Ainda, segundo esse autor, a interação pode ser um instrumento de recuperação da confiança dos cidadãos. 
Raupp e Pinho (2011) afirmam que o governo eletrônico (e-gov) promove uma aproximação entre o ente governamental e o cidadão contribuindo com uma maior democratização dos processos. Asseguram também que um dos mecanismos utilizados para pôr em prática/operacionalizar o governo eletrônico é a implementação de portais eletrônicos. Parte da evolução do e-gov é compreender a inclusão digital e também que o cidadão é o grande usuário dos serviços eletrônicos concedidos pelo governo (BALBE, 2010).

Desse modo, Jambeiro, Sobreira e Rabelo (2009) afirmam que, nos últimos anos, a transparência da gestão pública vem se beneficiando com o uso crescente das Tecnologias de Informação e Comunicação (TICs). Como consequência, as TICs, de acordo com os autores (p. 5) "permitem uma interação mais rápida, prática e dinâmica entre governo e sociedade", dado que são utilizadas pela administração pública para disponibilizar informaçóes para que sejam rapidamente localizadas e utilizadas.

O desenvolvimento da internet juntamente com o das TICs tornou o interesse do governo em relação à divulgação das informaçóes maior, pois eles parecem buscar cada vez mais a informatização dos seus serviços (JAMBEIRO; SOBREIRA; RABELO, 2009). Mas, asseguram os autores, a simples criação de websites para fazer divulgaçóes das informaçóes da gestão pública não garante uma gestão transparente. Sustentam ainda a ideia de que a adoção das TICs não é um objetivo, já que são ferramentas fundamentadas para atingir os objetivos propostos, sendo dois deles a transparência e a eficiência da gestão.

Nesse sentido, Medeiros e Guimarães (2006) elucidam que as TICs mudam a forma como a gestão pública é abordada, ou seja, faz com que cidadãos, atores governamentais e não governamentais queiram ter acesso ao governo de uma forma cada vez mais rápida e fácil, com a perspectiva de que os programas governamentais estejam focados em suas necessidades. Embora a evolução das TICs tenha possibilitado o feedback de uma forma mais aberta, “[...] não é possível afirmar que isso tenha tornado os governos mais transparentes ou democráticos [...]" (LACERDA, 2016, p. 22). Isso porque a transparência não depende apenas de quão visível é a informação, mas também se ela é disponibilizada de forma clara ao cidadão (ANGÉLICO, 2012).

De acordo com Lima Filho et al. (2011), há ainda grandes desafios a serem superados no Brasil em se tratando da transparência do poder público, tanto por parte do governo quanto da sociedade. Tais desafios são:

[...] a incipiente participação popular; dificuldade em encontrar linguagem compreensível na publicizaçấo das informaçôes; a falta de confiança nos representantes; ausência de identidade entre governantes e governados; o baixo grau de escolaridade de grande parte da população e a falta e assimetria das informações (LIMA FILHO et al., 2011, p. 20).

Considera-se, nesta perspectiva, que a institucionalização de uma lei, como a LAI, é apenas uma das fases na construção de uma política de transparência no país. Para ter êxito, a lei deve se converter em açóes do Executivo, Legislativo e Judiciário, proporcionando aos cidadãos um maior conhecimento dos atos da gestão pública e, dessa forma, buscando extinguir a desconfiança sem que acabe o interesse (PAES, 2011). 
Dessa forma, a divulgação via internet dos atos da gestão pública se torna o meio mais eficiente para conferir transparência às informaçóes, visto que o sistema de consultas on-line permite aos usuários a busca de informaçôes, através de filtros, de acordo com os interesses de cada cidadão (SOARES, 2013). Tem-se, assim, a cultura da transparência, a qual produz um impacto social significativo, uma vez que o controle dos atos da gestão pública são elementos substanciais ao exercício da democracia (BLANCHET; AZOIA, 2017).

Por fomentar a cultura da transparência, a LAI prevê duas particularidades que são fundamentais para seu entendimento: transparência ativa e transparência passiva. A transparência ativa é a divulgação de informaçóes de forma espontânea pelo poder público. Já quando se fala em transparência passiva, significa que "os atores estatais ficam obrigados a implementar procedimentos adequados e atender os pedidos de informações requisitados pelos cidadãos à administração pública" (SILVA; CRUZ; SPINELLI, 2014, p. 6). Zuccolotto, Teixeira e Riccio (2015) ressaltam que a transparência passiva se refere à obrigação do Estado em disponibilizar para todos os cidadãos o acesso aos documentos oficiais, exceto os que estiverem protegidos legalmente por motivos de segurança nacional, investigação pública, etc.

A escala utilizada neste trabalho para medir a transparência dos municípios foi escolhida por apresentar uma metodologia que permite mensurar tanto transparência ativa, quanto passiva dos entes públicos investigados, sendo este o diferencial da EBT. Alguns trabalhos investigaram a transparência pública nos municípios brasileiros, enfatizando a observaçáo dos respectivos portais eletrônicos, indo ao encontro desta investigação. Raupp e Pinho (2011) avaliaram as condiçóes de prestação de contas em portais eletrônicos de 17 câmaras municipais de Santa Catarina com população superior a 50.000 habitantes. Os resultados apontaram para uma alta capacidade de os portais promoverem a transparência dos atos públicos, porém baixa capacidade no que diz respeito a participação dos cidadãos com o ente público.

Santos, Carniello e Oliveira (2013) analisaram a forma como os 39 municípios da região metropolitana do Vale da Paraíba disponibilizavam as informações sobre a administração pública através da internet. A coleta dos dados foi realizada nos portais eletrônicos dos municípios da regiáo investigada. Para a coleta foram estabelecidos alguns critérios de análises de conteúdo, como: se há a disponibilização dos contatos (diretos) dos gestores públicos; dos serviços online; das contas públicas do município; se há um aviso sobre os instrumentos de participação que estão formalmente institucionalizados; informações sobre quais públicos são contemplados através do portal; se há o uso de mídias sociais para a ampliação do diálogo com o cidadão; se as leis municipais são disponibilizadas e se há informaçōes sobre as açōes da gestão municipal. Os resultados indicaram que, em cada microrregião avaliada, ao mesmo tempo em que alguns municípios cumprem com todas as obrigaçôes legais, outros atendem somente o mínimo previsto em lei e, não obstante, existem casos ainda que nem o que está estabelecido em lei é cumprido.

\subsection{Estudos anteriores sobre transparência na gestáo pública}

Sob o arcabouço teórico da transparência e dos fatores que a ela estão relacionados, diversos autores buscaram identificar a transparência pública a partir de portais eletrônicos, 
como o estudo de Machado, Marques e Macagnan (2013), que mensuraram o nível de transparência dos municípios do estado do RS cuja população é superior a 50 mil habitantes através da evidenciação de informaçôes obrigatórias nos portais eletrônicos em se tratando da LRF e da LAI. Os resultados indicaram que os 41 municípios investigados apresentam baixo nível de transparência das informaçôes obrigatórias, mostrando uma subutilização da internet para as atividades em questão.

Staroscky et al. (2014) investigaram a transparência pública municipal nos 9 municípios que fazem parte da Secretaria de Desenvolvimento Regional (SDR), de Chapecó, em Santa Catarina. Para análise dos dados, realizaram-se consultas nos portais eletrônicos dos municípios estudados para verificar o grau de atendimento à legislação e, a partir disso, o nível de transparência de cada um dos portais foi mensurado através da metodologia Multicritério de Apoio à Decisão Construtivista (MCDA-C). Obteve-se como resultados um baixo nível de transparência nos portais analisados, pois além de dificuldades de acesso em alguns portais, há também diferenças em relação às informaçóes contidas nos sites.

Bernardes, Santos e Rover (2015) avaliaram os municípios da regiáo Sul do Brasil, que incluem os estados de Rio Grande do Sul, Santa Catarina e Paraná, a partir de critérios estabelecidos na LAI. Os resultados indicaram que, dos 479 municípios investigados, apenas 8,53\% apresentam em seus portais eletrônicos algum indício da presença da LAI. Segundo os autores, são resultados alarmantes, uma vez que demonstram o descumprimento à legislação, fazendo com que o cidadão tenha participação reduzida nos processos democráticos dos entes governamentais. Os autores também indicaram "desatenção" na estrutura dos portais eletrônicos, na apresentação dos links, assim como nos textos dedicados à LAI, reiterando que grande parte do problema está na forma como esses portais estão estruturados e suas informações estão disponibilizadas, pois não seguem nenhuma estrutura lógica.

Da Silva, Kumegawa e Vasconcelos (2016) compararam os estágios de transparência e de disponibilidade de informações dos portais eletrônicos das prefeituras de Curitiba, Belo Horizonte, Salvador e Porto Alegre. Como resultados, percebeu-se que existe semelhança entre os níveis de governo eletrônico nesses portais, mas em alguns aspectos, alguns estâo mais desenvolvidos do que outros. É o caso da cidade de Porto Alegre, que obteve as maiores notas, ou seja, apresentou maior evolução no nível de governo eletrônico.

Em análise da transparência passiva, Raupp e Pinho (2016) avaliaram o atendimento às exigências legais pelas câmaras municipais cuja população fosse superior a 300.000 habitantes. Os resultados revelaram pouca transparência passiva perante a tecnologia disponível, pois há câmaras que descumprem as leis que regulamentam a transparência.

Já o estudo de Brocco et al. (2018) teve como objetivo investigar os fatores que explicam o nível de transparência dos municípios de médio e grande porte do RS. Integraram a amostra os 43 municípios com mais de 50 mil habitantes. Para essa investigação, um índice baseado na LRF e na LAI foi construído. Como resultados, obtiveram $71 \%$ de média do nível de transparência desses municípios. Além disso, entre os fatores pesquisados, o Índice Firjan de Desenvolvimento Municipal foi o único que, estatisticamente, explica o nível de transparência dos municípios. Através desse estudo ficou claro que os cidadãos com boa empregabilidade, educação e melhores condiçóes de saúde, possuem melhores condiçóes para efetivar a participação popular na administração pública de seus municípios. 
Percebe-se uma ênfase na avaliaçấo de municípios de grande porte, sendo esta uma das justificativas para o desenvolvimento do trabalho de Santos (2017) e Santos e Visentini (2018), que analisaram a transparência da gestão pública dos 25 municípios que fazem parte do COREDE Missóes, predominantemente de pequeno porte. Em Santos (2017), a EBT foi aplicada na verificação do grau de cumprimento às normas da LAI através do portal eletrônico de cada município. Os resultados indicaram que os níveis de transparência dos municípios investigados sáo considerados baixos. Já em Santos e Visentini (2018) foi utilizado o Índice de Transparência na Gestão Pública Municipal (ITGP-M), além de entrevistas semiestruturadas com 10 gestores públicos municipais, realizadas entre os anos de 2016 e 2017 para compreender como as práticas de transparência são percebidas. Os resultados apontam para uma dificuldade quando se trata de disponibilizar informaçóes, isto é, informaçōes obrigatórias são fornecidas sem restriçōes, enquanto os demais dados são "filtrados" pela administração, impedindo, portanto, a praticabilidade da LAI.

\section{Metodologia}

Esta pesquisa caracteriza-se como descritiva e quantitativa com obtenção de dados primários através dos sites dos 25 municípios do COREDE Missóes, população investigada nessa pesquisa. Os COREDES foram instituídos legalmente com o objetivo de ser um espaço para discussões sobre estratégias, políticas e açôes visando o desenvolvimento regional sob a forma de associaçōes civis sem fins lucrativos (BÜTTENBENDER; SIEDENBERG; ALLEBRANDT, 2011). Cada COREDE aprova o seu Estatuto ou Regimento Interno, conforme a Lei $\mathrm{n}^{\circ} 10.283$, mas todos possuem a mesma estrutura organizacional composta pelos órgáos: 1) Assembleia Geral Regional; 2) Conselho de Representantes; 3) Diretoria Executiva; 4) Comissōes Setoriais (COELHO; FRIZZO; MARCONDES, 2010).

De acordo com Dallabrida (2010), Coelho, Frizzo e Marcondes (2010) e Bertê et al. (2016), o Governo do Estado do RS ordenou que a sociedade se organizasse em Conselhos Regionais de Desenvolvimento para que ficasse à par e pudesse ter maior participação nas açôes da gestáo. Com a finalidade de implantar os COREDES/RS, houve uma ampla mobilizaçáo de diferentes setores da sociedade para estabelecer regióes apoiadas em identidades regionais. O resultado, portanto, foi a criaçâo dos Conselhos, atualmente 28.

O COREDE Missões é composto pelos seguintes municípios (Figura 1): Bossoroca, Caibaté, Cerro Largo, Dezesseis de Novembro, Entre-Ijuís, Eugênio de Castro, Garruchos, Giruá, Guarani das Missóes, Mato Queimado, Pirapó, Porto Xavier, Rolador, Roque Gonzales, Salvador das Missōes, Santo Ângelo, Santo Antônio das Missōes, São Luiz Gonzaga, São Miguel das Missóes, São Nicolau, São Paulo das Missões, São Pedro do Butiá, Sete de Setembro, Ubiretama e Vitória das Missóes. A maioria dos 25 municípios que abrangem o COREDE Missōes/RS é de pequeno porte (IBGE, 2010), sendo o menor deles Mato Queimado (1.799 habitantes) e o maior Santo Ângelo (76.275 habitantes).

Segundo Bertê et al. (2016), a base econômica do COREDE Missōes possui maior foco no setor agropecuário, destacando-se a criação de suínos e bovinos, além dos cultivos de milho, trigo, mandioca e soja. Em se tratando da indústria, Wbatuba et al. (2017) revelam que esse setor está ligado ao beneficiamento de produtos primários e, os setores de 
comércio e serviços abastecem e dão suporte aos setores primários e secundários oriundos da agropecuária.

Figura 1 - Mapa do COREDE Missóes/RS

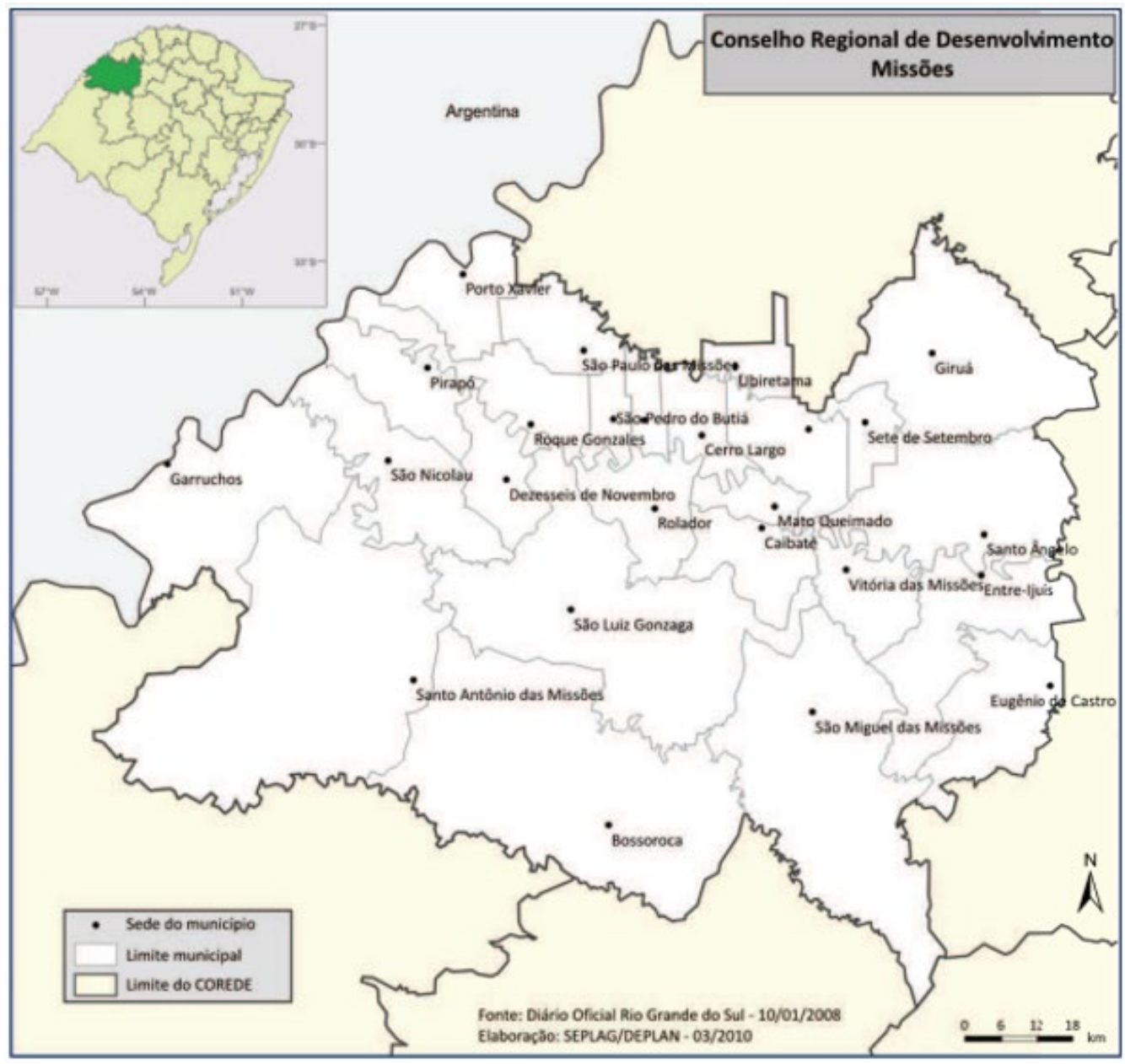

Fonte: Secretaria do Planejamento, Mobilidade e Desenvolvimento Regional, 2015.

Para verificar o nível de transparência dos municípios integrantes do COREDE Missóes, aplicou-se a avaliação descrita pela EBT, sendo possível a elaboraçấo de um ranking de transparência, o qual foi comparado com a última análise da EBT 3.0 (CGU, 2016) e com os resultados de Santos (2017).

A metodologia da EBT consiste no preenchimento de um checklist, sendo possível somente respostas "SIM" ou "NÃO" para cada quesito, com a exceção de quando não forem encontrados os portais eletrônicos ou quando estes estiverem fora do ar, neste caso podendo ser utilizado os termos "Não Localizado" ou "Site Fora do AR" (CGU, 2016). O preenchimento de todo o checklist resulta em uma nota de 0 a 10 pontos, sendo $25 \%$ que informam sobre a regulamentação do acesso à informação e $75 \%$ sobre a existência 
e funcionamento do Serviço de Informação ao Cidadão (SIC). A pontuação final obtida para cada município corresponde à quantidade de requisitos atendidos no checklist. Tal pontuação varia de 0 a 3600 pontos e então é convertida de 0 a 10 pontos para uma melhor compreensão dos avaliadores e também da sociedade através da fórmula: Nota = (Pontuação atingida / 3600) * 10 (CGU, 2016).

Os portais eletrônicos dos 25 municípios foram avaliados conforme o manual da EBT, ou seja, verificando o real cumprimento da LAI e da transparência passiva através da existência e funcionamento do SIC, conforme Quadro 1. Dessa forma, para identificar as homepages dos municípios foi utilizada a plataforma on-line do Google (www.google.com. br) e adotou-se como expressão padrão "Prefeitura Municipal de [nome do município]". Foram consideradas válidas as homepages que possuiam a extensão ".gov", dada pelo seguinte formato "nomedomunicípio.sigladoestado.gov.br" (CRUZ et al., 2012).

Quadro 1 - Aplicação da EBT a partir da avaliação dos portais eletrônicos

\begin{tabular}{|c|l|}
\hline $\mathrm{N}^{\circ}$ & \multicolumn{1}{|c|}{ Fato } \\
\hline $\mathbf{1}$ & O regulamento da LAI foi localizado na página eletrônica? \\
\hline $\mathbf{2}$ & O ente regulamentou a LAI? \\
\hline $\mathbf{3}$ & O ente público regulamentou a criação do SIC? \\
\hline $\mathbf{4}$ & $\begin{array}{l}\text { Existe a previsão das autoridades que podem classificar a informação quanto ao grau de } \\
\text { sigilo? }\end{array}$ \\
\hline $\mathbf{5}$ & Existe a responsabilização do servidor em caso de condutas ilícitas? \\
\hline $\mathbf{6}$ & O ente regulamentou a existência de pelo menos uma instância recursal? \\
\hline $\mathbf{7}$ & Existe indicação precisa no site de um SIC físico, ou seja, atendimento presencial? \\
\hline $\mathbf{8}$ & Há alternativa de enviar pedidos de forma eletrônica ao SIC? \\
\hline $\mathbf{9}$ & $\begin{array}{l}\text { Para realização dos pedidos de informação, são exigidos dados de identificação do } \\
\text { requerente que dificultem ou impossibilitem o acesso à informação? }\end{array}$ \\
\hline $\mathbf{1 0}$ & Apresenta possibilidade de acompanhamento posterior da solicitaçáo? \\
\hline $\mathbf{1 1}$ & O ente público cumpre com os prazos para resposta das solicitaçôes? \\
\hline $\mathbf{1 2}$ & Respondeu ao que se perguntou, atendendo ao pedido de informação? \\
\hline
\end{tabular}

Fonte: EBT, 2018.

Quando encontrado o SIC nos portais eletrônicos dos entes investigados, era realizados os pedidos de informação, de acordo com o manual da EBT, para aferir os itens do itemk 8 ao 12 do Quadro 1. Os pedidos de informação são quatro e abrangem às áreas da saúde, educação, assistência social e regulamentação da LAI.

As notas finais proporcionaram a criação de um ranking dos entes avaliados. A EBT é uma metodologia de fácil acesso e que permite informaçóes substanciais e, nesta pesquisa, permitiu uma avaliação da transparência nos municípios do COREDE Missôes, assim como uma comparação com a versão 3.0 da EBT (realizada pela CGU, 2016) e com o estudo de Santos (2017), que coletou os dados de outubro de 2016 à janeiro de 2017. Em se tratando da versáo 3.0 da EBT, realizada em 2016, cabe ressaltar que dos 25 municípios que compóem o COREDE em estudo, apenas 6 receberam a avaliação da CGU: Guarani 
das Missões, Pirapó, Porto Xavier, Roque Gonzales, São Paulo das Missões e Vitória das Missóes.

A observação e análise dos portais eletrônicos dos municípios que integram o COREDE Missóes ocorreram no período de junho de 2018 até julho de 2018, respeitando o período de 20 dias para a obtenção de respostas por parte dos entes públicos, prazo que poderia ser prorrogado por mais 10 dias mediante justificativa dos mesmos, conforme a LAI (BRASIL, 2011). Os dados foram tabulados e analisados descritivamente com auxílio do software Microsoft Excel 2016.

\section{Análise de resultados}

No que concerne à transparência ativa, o checklist foi preenchido conforme exposto na metodologia deste trabalho, nos 25 portais eletrônicos das prefeituras estudadas. Já em relação à transparência passiva, de acordo com o manual da EBT, os pedidos de informaçáo (Saúde, Educação, Assistência Social e Regulamentação da LAI) foram enviados, cumprindo o prazo determinado pela LAI. Cabe ressaltar que para todos os entes públicos tal critério foi rigorosamente atendido.

Apesar disso, encontraram-se alguns obstáculos durante o período de análise dos portais eletrônicos. No caso do município de Entre-Ijuís, ao acessar o portal eletrônico, era obrigatório que toda e qualquer pessoa que fizesse o pedido de informação efetuasse um cadastro. Em consequência, ao finalizar o cadastro, a página seguinte seguia com a informação de erro no site. Também, ao averiguar o Decreto do município que regulamenta a LAI, percebeu-se que o mesmo não estava condizente com o município. Apesar de nesta pesquisa o cadastro não ter sido concluído por erro no site, ressalta-se que Santos (2017) obteve sucesso nesta etapa.

Outro município com dificuldades ao acessar o portal eletrônico nesta pesquisa foi Guarani das Missóes, pois o site possuía o ícone do Acesso à Informação, mas não era possível acessá-lo. Ainda, o site não tinha e-sic, Ouvidoria e Fale Conosco, impossibilitando, portanto, qualquer forma de comunicação entre ente público e cidadão.

Nos portais eletrônicos dos municípios de São Pedro do Butiá e Vitória das Missóes, ao encontrar o SIC e realizar os pedidos de informação, os sites não geravam um protocolo para acompanhamento, bem como das respostas. Por fim, no município de Ubiretama, os pedidos de informação foram realizados pela Ouvidoria, pelo falo do site não ter um $e$-sic.

Para fins de análise, ressalta-se que foram realizadas tentativas nos portais eletrônicos dos municípios de Entre-Ijuís, São Pedro do Butiá e Vitória das Missões durante um período de trinta dias, mais especificamente, de 11 de Junho à 11 de Julho. No caso do município de Entre-Ijuís, não foi possível realizar o cadastro para efetivação do pedido, pois no site relatava que "Ocorreu um erro na inclusão dos dados do Solicitante". Santos (2017) conseguiu realizar os pedidos de informação em todos os municípios integrantes do COREDE Missóes, enquanto que, nesta pesquisa, não foi possível enviar para os quatro municípios citados anteriormente.

É indispensável salientar que em todos os requisitos o manual da EBT foi cumprido, portanto, os pedidos de informação foram enviados em nome de quatro pessoas diferentes. 
É perceptível, através dos resultados encontrados e dos pedidos de informação, o não cumprimento da LAI por parte de algumas prefeituras no que se refere tanto à transparência ativa, quanto passiva. Nota-se que os municípios do COREDE Missóes náo possuem portais eletrônicos padronizados, resultando em uma dificuldade ao solicitante dos pedidos de informação, indicando a "desatenção" na estrutura desses portais, já mencionada por Bernardes, Santos e Rover (2015).

Quando há quaisquer obstáculos que dificultem o acesso do cidadão à informação desejada, além de uma violaçáo à Lei, o mesmo fica impossibilitado de acompanhar os atos praticados na gestão da sua cidade e até mesmo do país. Corroborando, Silva, Cruz e Spinelli (2014) afirmam que, além de haver transparência em todas as informaçóes das atividades praticadas pelos administradores (exceto àquelas em sigilo), os cidadãos devem conseguir compreendê-las.

Em análise posterior, com relação à transparência passiva, percebeu-se que apenas 9 municípios de um total de 25 responderam todas as perguntas solicitadas no prazo especificado pela EBT e de forma satisfatória. Há também aqueles municípios em que a resposta foi satisfatória, porém o prazo não foi cumprido para todas as perguntas (Quadro 2).

Quadro 2 - Municípios que responderam aos pedidos de informação dentro do prazo da EBT e municípios que não cumpriram com o prazo

\begin{tabular}{|l|l|}
\hline $\begin{array}{c}\text { Municípios que atenderam todos os pedidos } \\
\text { de informaçáo e prazos }\end{array}$ & $\begin{array}{l}\text { Municípios que atenderam aos pedidos de } \\
\text { informaçáo mas não cumpriram com o prazo }\end{array}$ \\
\hline Cerro Largo & Bossoroca \\
\hline Dezesseis de Novembro & Giruá \\
\hline Eugênio de Castro & Roque Gonzales \\
\hline Mato Queimado & São Nicolau \\
\hline Porto Xavier & Sete de Setembro \\
\hline Santo Ângelo & \\
\hline Santo Antônio das Missóes & \\
\hline São Luiz Gonzaga & \\
\hline São Paulo das Missóes & \\
\hline
\end{tabular}

Fonte: Elaborado pelos autores, 2020.

Na pesquisa de Santos (2017), em 14 municípios os pedidos de informação foram atendidos parcialmente. Ressalta-se que, nesta parte da pesquisa, cabe aos avaliadores considerarem ou não as respostas. Portanto, nesse estudo não foram consideradas respostas parciais, pois a qualidade das respostas não foi avaliada, mas sim se as solicitaçôes foram atendidas. Além disso, uma das diferenças entre as pesquisas é que no estudo de Santos (2017) apenas Porto Xavier e Mato Queimado atenderam totalmente aos pedidos de informação enviados, sendo considerados transparentes na forma passiva.

Assim como no estudo desenvolvido por Raupp e Pinho (2016), fica claro que não adianta dispor de tecnologia se a mesma não for utilizada para um propósito maior. Se os canais de comunicação não são desenvolvidos, não há possibilidade dos pedidos serem 
realizados, consequentemente, da interação entre gestão pública/cidadão. É visível que padronizar os sistemas de governo eletrônico é um desafio, contudo, tal desafio faz-se necessário quando se entende que a estrutura existente no governo eletrônico não possui êxito (DA SILVA; KUMEGAWA; VASCONCELOS, 2016).

Dando continuidade a análise, dos 25 municípios estudados nessa pesquisa, apenas 48\% regulamentaram a LAI: Caibaté, Cerro Largo, Eugênio de Castro, Giruá, Porto Xavier, Rolador, Roque Gonzales, Santo Antônio das Missóes, São Luiz Gonzaga, São Nicolau, São Paulo das Missóes e São Pedro do Butiá. Apesar de esses municípios cumprirem com a LAI no que diz respeito a decretar sua própria legislaçáo com base na Lei 12.527/2011, todos excederam o prazo de 180 dias para regulamentá-la.

A primeira diferença encontrada entre a pesquisa de Santos (2017) e esta pesquisa realizada no ano de 2018 foi que, no estudo de Santos (2017), apenas sete municípios do COREDE Missóes haviam regulamentado a LAI por instrumento legal. A partir dos resultados encontrados neste estudo, nota-se que no período de um ano, mais cinco municípios regulamentaram a LAI, conforme Quadro 3, totalizando 12 municípios.

Quadro 3 - Municípios que regulamentaram a LAI

\begin{tabular}{|l|l|}
\hline \multicolumn{1}{|c|}{$\begin{array}{c}\text { Municípios com a LAI regulamentada no } \\
\text { estudo de Santos (2017) }\end{array}$} & \multicolumn{1}{c|}{$\begin{array}{c}\text { Municípios com a LAI regulamentada na } \\
\text { pesquisa de 2018 }\end{array}$} \\
\hline Caibaté & Eugênio de Castro \\
\hline Cerro Largo & Rolador \\
\hline Giruá & Roque Gonzales \\
\hline Porto Xavier & Santo Antônio das Missôes \\
\hline Sáo Paulo das Missóes & São Pedro do Butiá \\
\hline Sáo Luiz Gonzaga & \\
\hline Sáo Nicolau & \\
\hline
\end{tabular}

Fonte: Elaborado pelos autores, 2020.

Posteriormente à análise da regulamentação da LAI (peso de $25 \%$ no checklist da EBT), os pedidos de acesso à informação (peso de 75\%) foram analisados a fim de aferir a transparência passiva dos municípios. Como consequência dessas duas análises, uma nota foi atribuída para cada município, conforme Gráfico 1, que compara as notas desta pesquisa com as do estudo de Santos (2017) e da CGU (2016), EBT versão 3.0. 
Gráfico 1 - Comparação dos rankings da pesquisa realizada em 2018 com o estudo de Santos (2017) e EBT 3.0

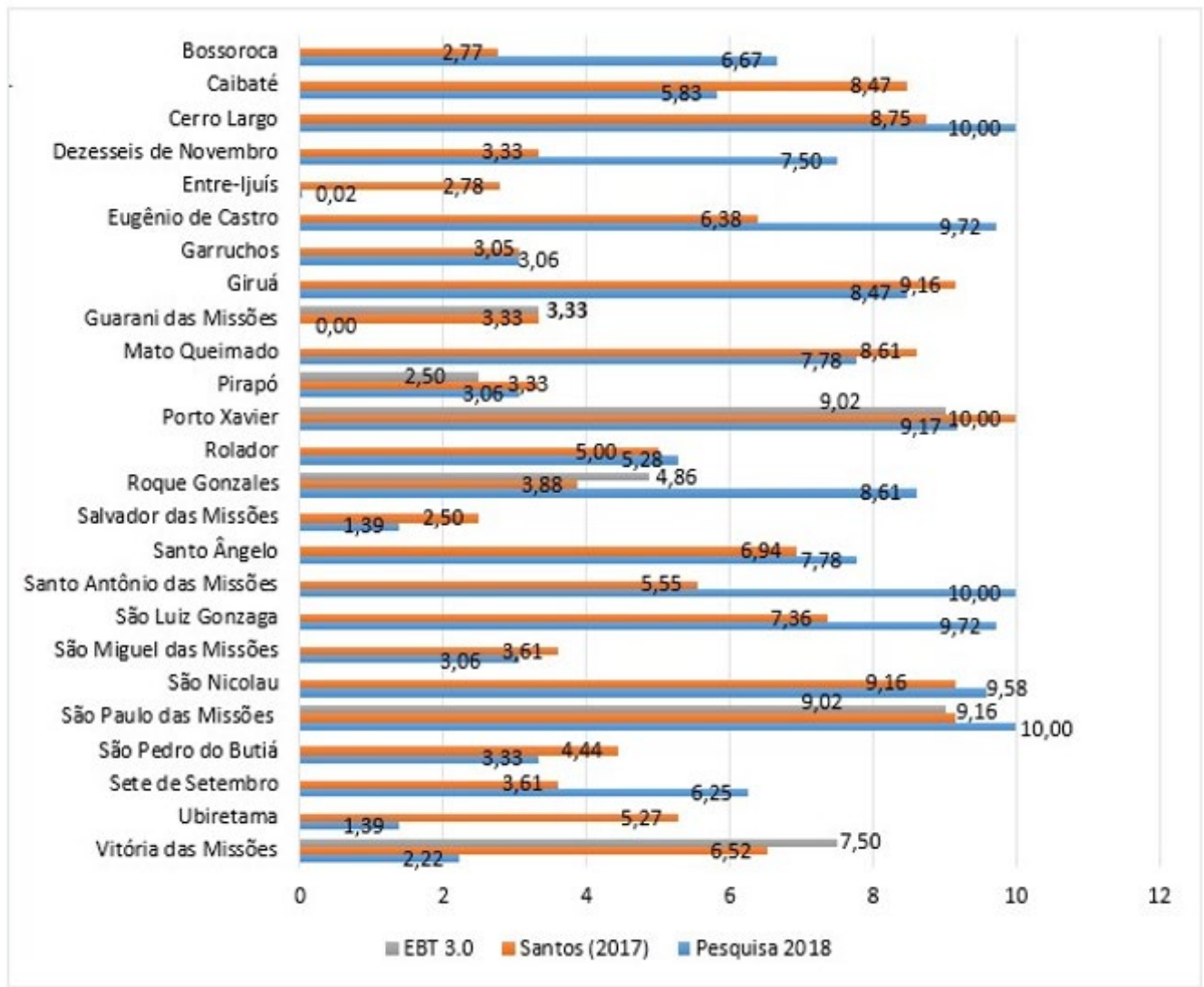

Fonte: Elaborado pelos autores a partir dos dados da pesquisa, 2020.

Os municípios que integram o COREDE Missóes e que receberam avaliação da CGU em 2016 foram 6 (seis): São Paulo das Missóes, Porto Xavier, Vitória das Missões, Roque Gonzales, Guarani das Missões e Pirapó. A comparação entre a avaliação da Controladoria Geral da União (CGU) com a pesquisa realizada permite uma análise mais detalhada, começando por São Paulo das Missões, município que se destacou por obter pontuação máxima nesta pesquisa.

A diferença encontrada se deu pelo fato de não existir, na análise da CGU (2016), a previsão das autoridades que possam classificar a informação quanto ao grau de sigilo na lei regulamentada pelo município. Além disso, na análise da CGU (2016), não foi possível localizar a indicação do SIC presencial na homepage da prefeitura.

O município de Porto Xavier obteve a mesma pontuação na avaliação da CGU (2016) pelos mesmos motivos que São Paulo das Missóes. Apesar disso, nota-se que, no estudo de Santos (2017) o único município a alcançar nota 10,00 foi Porto Xavier, pois atendeu todos os quesitos avaliados na EBT. Nesta pesquisa (2018), o munícipio de Porto 
Xavier obteve uma nota próxima da pontuação máxima, porém não atendeu ao pedido de informação sobre a regulamentaçáo da LAI, que solicitava que a norma de seu município fosse enviada junto à resposta.

Nesta pesquisa, os municípios a alcançarem pontuação máxima foram Cerro Largo, Santo Antônio das Missóes e São Paulo das Missões, pelo fato de atenderem a todos os requesitos da EBT. Os municípios de São Luiz Gonzaga e Eugênio de Castro não atenderam aos requisitos de indicação de endereço do SIC físico e dos horários de funcionamento, respectivamente.

A pontuação do município de Vitória das Missóes, nesta pesquisa (2018), obteve um decréscimo de 5,28 pontos se comparada com a avaliação da CGU (2016), conforme Gráfico 1. Tal divergência ocorreu, pois, na análise da CGU (2016), encontrou-se a indicação do SIC presencial, bem como de endereço, telefone e horário. Além disso, todos os quesitos exigidos no checklist no que compete à transparência passiva foram cumpridos.

Já na análise feita neste estudo (2018) algumas diferenças foram encontradas: a LAI foi localizada no site da prefeitura, e os únicos quesitos cumpridos no que compete à transparência passiva foram as indicaçóes do SIC físico, pois não foi possível mandar as perguntas, consequentemente, sem obtenção de respostas. Esses resultados assemelhamse à pesquisa de Santos, Carniello e Oliveira (2013), uma vez que existem diferenças na forma como os municípios fazem uso, ou não, da obrigatoriedade legal em disponibilizar informaçōes sobre a gestão pública.

Em se tratando do município de Roque Gonzales, percebe-se através do Gráfico 1, que houve um aumento de 3,75 pontos nesta pesquisa se comparada a EBT 3.0. Na avaliação feita pela CGU (2016) não foi possível encontrar na LAI do município a previsão de classificação quanto ao grau de sigilo. Além do mais, não havia indicação do SIC presencial. Já na parte que compete ao prazo das perguntas e respostas está em branco, deduzindo-se que as perguntas não puderam ser enviadas, apesar de existir a possibilidade de enviá-las de forma eletrônica. As diferenças encontradas entre as análises foram que, apesar de ter uma elevação na pontuação, nesta pesquisa não foi possível identificar os horários de funcionamento do SIC físico no site da prefeitura. Porém, pôde-se enviar as perguntas e todas foram respondidas, contudo os prazos dos questionamentos sobre Saúde, Educação e Assistência Social não foram cumpridos.

O município de Guarani das Missōes não pontuou nesta pesquisa, pelo fato de não ter cumprido com nenhum requisito exigido pela LAI, ou seja, além da LAI não ter sido localizada no portal eletrônico, não há indicação de um SIC físico. E ainda, na página eletrônica do município não foi possível localizar o $e$-sic, Ouvidoria ou até mesmo o Fale Conosco, como citado anteriormente.

É importante ressaltar que este município zerou a pontuação, por isso, no Gráfico 1, a única pontuação é a encontrada no estudo de Santos (2017) e na análise da EBT 3.0. Os 3,33 pontos da avaliação da CGU (2016) se justificam porque os únicos quesitos atendidos foram a indicação de endereço e telefone, além da alternativa de enviar os pedidos de acesso à informação eletronicamente. Também consta na avaliação da CGU (2016) que somente a pergunta referente à Saúde foi respondida no prazo e adequadamente. Tal resultado vai 
ao encontro do estudo de Staroscky et al. (2014), em que os entes públicos não utilizam da melhor maneira, ou ainda, não aproveitam os benefícios que a divulgação das informaçóes por meio da internet podem trazer à população e a própria gestáo pública.

Por fim, na análise do município de Pirapó, percebe-se um aumento de 0,56 pontos na pesquisa realizada no ano de 2018 , tendo em vista que a LAI foi localizada no site da prefeitura e também há a indicação do SIC presencial no site, bem como a indicação dos horários de atendimento do mesmo, quesitos que não foram cumpridos na avaliação da CGU (2016).

Na pesquisa de Santos (2017), ocupando a última posição no ranking, encontra-se o município de Salvador das Missóes, com nota 2,50, pois, segundo a autora, o município não regulamentou a LAI e, em se tratando da transparência passiva, atendeu apenas a indicação de endereço do SIC presencial, telefone e acompanhamento dos pedidos, pedidos estes que não foram respondidos. Já na pesquisa realizada em 2018, o único quesito que o ente cumpriu foi o de possibilitar, em seu portal, o envio dos pedidos em forma eletrônica por meio do $e$-sic, resultado em uma pontuação de 1,39 .

O município de Ubiretama obteve a mesma pontuação nesta pesquisa, pois assim como Salvador das Missões, o único quesito atendido também foi a possibilidade de envio dos pedidos na forma eletrônica, com a diferença de que foram feitos através da Ouvidoria. De acordo com Santos (2017), o SIC é uma das formas de possibilitar a comunicação do cidadão com a gestão pública, porém, na ausência de um SIC, os municípios podem criar o sistema de Ouvidoria ou o Fale Conosco. Enquanto na pesquisa de Santos (2017) em 4 municípios (Bossoroca, Dezesseis de Novembro, São Pedro do Butiá e Ubiretama) os pedidos de informação foram encaminhados na Ouvidoria ou Fale Conosco, nesta pesquisa verificou-se que apenas o município de Ubiretama não possui o $e$-sic, portanto, realizou-se o contato através da Ouvidoria.

Por fim, a nota quase nula do município de Entre-Ijuís justifica-se, nesta pesquisa, pelo mesmo motivo dos municípios de Ubiretama e Salvador das Missóes. A partir disso, no Quadro 4 é possível verificar os municípios que não atenderam a todos, ou deixaram de atender algum(ns) dos pedidos de informação, na pesquisa de Santos (2017) e na pesquisa atual.

Quadro 4 - Municípios que não atenderam aos pedidos de informação no estudo de Santos (2017) e na pesquisa atual

\begin{tabular}{|c|c|}
\hline $\begin{array}{c}\text { Municípios que não atenderam ao pedido de } \\
\text { informaçáo no estudo de Santos (2017) }\end{array}$ & $\begin{array}{c}\text { Municípios que náo atenderam ao pedido de } \\
\text { informação na pesquisa atual (2018) }\end{array}$ \\
\hline Dezesseis de Novembro & Caibaté \\
\hline Entre-Ijuís & Garruchos \\
\hline Garruchos & Giruá \\
\hline Guarani das Missões & Pirapó \\
\hline Pirapó & Rolador \\
\hline Roque Gonzales & Salvador das Missóes \\
\hline Salvador das Missóes & Sáo Miguel das Missóes \\
\hline
\end{tabular}




\begin{tabular}{|c|c|}
\hline $\begin{array}{c}\text { Municípios que não atenderam ao pedido de } \\
\text { informaçáo no estudo de Santos (2017) }\end{array}$ & $\begin{array}{c}\text { Municípios que náo atenderam ao pedido de } \\
\text { informação na pesquisa atual (2018) }\end{array}$ \\
\hline Sáo Miguel das Missóes & Sete de Setembro \\
\hline Sete de Setembro & Ubiretama \\
\hline
\end{tabular}

Fonte: Elaborado pelos autores, 2020.

O Quadro 4 mostra que alguns municípios repetem entre um ano e outro, ou seja, que nenhuma mudança aconteceu no transcorrer do período avaliado. Logo, os resultados até aqui encontrados permitem afirmar que os municípios investigados podem ser considerados pouco transparentes na forma passiva. Isso porque ainda existem entes públicos cujo portal eletrônico não possui estruturas para receber as solicitaçóes dos cidadãos, mesmo após sete anos da LAI ter sido ratificada. Esses resultados vâo ao encontro do de Machado, Marques e Macagnan (2013), pois revelam que os portais eletrônicos devem ser mais explorados como instrumento de interação entre Estado e sociedade.

Em geral, Santos (2017) concluiu em seu estudo que "a realidade dos municípios do COREDE Missóes não se apresenta de forma satisfatória no que tange a transparência evidenciada nos portais eletrônicos" (p. 85), pois somente 44\% (12) municípios obtiveram notas acima de 6,00 , e o restante alcançaram notas inferiores. Já nesta pesquisa, conforme Gráfico 1, 56\% (14) dos municípios investigados obtiveram notas acima de 6,00.

Conforme os resultados apontados, é perceptível uma pequena melhora em se tratando da transparência dos municípios do COREDE Missóes neste período de um ano (2017-2018). Apesar disso, nota-se que alguns portais ainda não estão estruturados para receber solicitaçôes dos cidadãos e não possuem as informaçôes necessárias para que os pedidos sejam efetuados, sendo esta uma forma de o administrador municipal desconhecer a indispensabilidade das informaçóes para o cidadão (RAUPP, 2016). A falta de padronização desses portais acaba dificultando o acesso às informações que o cidadão busca, pelo fato de muitas delas estarem incompletas ou até mesmo porque não se encontram no site.

Cabe aos gestores públicos compreender que, ao regulamentar a LAI, os municípios dão um passo importante em direção ao fortalecimento dos direitos dos cidadãos e do processo democrático, passando da cultura do sigilo para uma cultura de acesso, sendo a informação uma regra e o sigilo, a exceção. Logo, o atendimento a essas diretrizes contribui e facilita o acesso às informaçóes, além de aumentar e estimular a interação entre os cidadãos e o governo (BERNARDES; SANTOS; ROVER, 2015).

De modo geral, pôde-se perceber que os portais eletrônicos dos municípios estudados possuem uma baixa capacidade de contribuir para a construção da transparência, resultando, dessa forma, em uma tênue participação e interação dos cidadãos com os entes públicos, assim como na pesquisa de Raupp e Pinho (2011). Esses autores indicam que tal participação só é efetiva quando o solicitante recebe retorno da sua sugestão ou solicitação.

Os resultados desta pesquisa corroboram também com os de Raupp e Pinho (2016), que indicaram a pouca transparência passiva considerando a tecnologia disponível atualmente, mostrando que a tecnologia não é um obstáculo à transparência, mas sim os órgãos públicos, pois infringem uma série de regulamentaçóes sobre a transparência das 
açōes do governo. Dessa forma, ao limitar informaçōes, os governos acabam por dificultar a participação do cidadáo nos processos democráticos.

Percebe-se, através deste trabalho, que os municípios do COREDE Missōes/RS ainda precisam atravessar muitas barreiras para chegar a um nível de transparência pública desejado e, principalmente, nível este que esteja de acordo com a lei, visto que somente 12 dos 25 municípios investigados regulamentaram a LAI. Portanto, compete aos gestores de cada município fomentar a publicação e divulgação de informaçôes além das previstas na legislaçấo, ou seja, cumprindo com a responsabilidade de informar os cidadãos sobre os rumos e passos da gestão atual (STAROSCKY et al., 2014).

Por fim, pode-se afirmar, indo ao encontro da pesquisa de Santos (2017), que na maior parte dos municípios do COREDE Missóes os dados encontrados nos portais eletrônicos são àqueles obrigatórios por lei e, portanto, disponibilizados sem ressalvas, enquanto o restante das informaçóes e dados passam por um "filtro" da gestão municipal para a decisão sobre sua publicação ou não. Obstáculos como estes encontrados nesses municípios mostram que ainda existe certa resistência à disponibilização de informações por parte dos administradores, consequentemente, impedindo a concretizaçấo e efetividade da LAI.

\section{Consideraçóes finais}

O presente trabalho teve como objetivo avaliar, para o ano de 2018, através EBT, o nível de transparência nos portais eletrônicos das prefeituras que fazem parte do COREDE Missóes-RS, bem como realizar a comparação com a última análise da EBT versáo 3.0 (CGU, 2016) e com o estudo de Santos (2017). De modo geral, observou-se que os municípios investigados são pouco transparentes, principalmente em se tratando de transparência eletrônica, isso porque poucos municípios divulgam todas as informaçóes previstas em lei. Apenas Cerro Largo, Santo Antônio das Missões e São Paulo das Missões obtiveram pontuação máxima. Em contrapartida, o município de Guarani das Missóes obteve pontuação nula, pois não cumpriu com os requisitos solicitados pelo checklist da EBT e, consequentemente, com a LAI.

Os achados permitiram uma comparação com a versão 3.0 da EBT. Tem-se como resultados que as pontuaçóes mais significativas da análise da CGU (2016) foram dos municípios de São Paulo das Missōes e Porto Xavier, enquanto as pontuações menores ficaram com os municípios de Guarani das Missōes e Pirapó. Para estes municípios, a avaliação desta investigação encontrou pontuação semelhante àquelas registradas pela CGU (2016), indicando paridades nos cenários dos portais eletrônicos avaliados em ambas as pesquisas, mesmo em anos diferentes de análise.

Além disso, também se comparou os resultados encontrados com o estudo de Santos (2017). As principais diferenças observadas entre os estudos é que em Santos (2017) apenas sete municípios integrantes do COREDE Missóes haviam regulamentado a LAI por instrumento legal, enquanto nesta investigação foram identificados 12 municípios. Também, em Santos (2017) apenas um município foi classificado com nota máxima (Porto 
Xavier), já nesta pesquisa foram três. Quanto à pontuação mínima, em Santos (2017) foi de 2,50 (Salvador das Missóes), enquanto nesta pesquisa foi 0,00 (Guarani das Missóes).

É perceptível, conforme os resultados apontados, que houve uma melhora em se tratando da transparência dos municípios do COREDE Missóes neste período, visto que, quando comparados os resultados com a pesquisa de Santos (2017), 52\% dos municípios investigados tiveram aumento na pontuação, enquanto o restante piorou substancialmente suas notas, como Entre-Ijuís e Guarani das Missões. Esses resultados revelam que, após dois anos de diferença entre as pesquisas, ainda existem municípios que não estão adequados aos parâmetros legais no que diz respeito à transparência pública, indicando desatenção à legislação. O interesse em comparar esta pesquisa com a de Santos (2017) foi de verificar as mudanças que ocorreram nesse período, pois se entende que a troca de gestor municipal em alguns municípios e o decorrer dos anos poderiam estimularmelhoras em relação ao cumprimento dos requisitos da LAI.

Os resultados também permitem afirmar que alguns portais ainda não estão estruturados para receber solicitaçôes dos cidadãos e não possuem os recursos necessários para que os pedidos sejam efetuados. Um dos motivos que podem justificar esta situação é a terceirização dos serviços de divulgação e atualização das informações nos portais eletrônicos. Santos e Visentini (2018) indicaram que municípios que terceirizam as informaçóes de seus portais são justamente aqueles que apresentam menor índice de transparência, como é a realidade dos pequenos municípios investigados.

Apesar disso, o aumento da pontuação de alguns municípios demonstra que as prefeituras, mesmo de porte pequeno, estão aderindo a cultura da transparência e não a cultura do sigilo, indo ao encontro dos pressupostos da LAI. Essa legislação foi constituída para que houvesse essa modificação na cultura, tornando o acesso à informação regra e o sigilo a exceção (BRASIL, 2011).

Observa-se que, de uma forma geral, os resultados encontrados nessa pesquisa assemelham-se com a maioria dos estudos realizados anteriormente (RAUPP; PINHO, 2011; SANTOS; CARNIELLO; OLIVEIRA, 2013; MACHADO; MARQUES; MACAGNAN, 2013; STAROSCKY et al., 2014; RAUPP; PINHO, 2016; SANTOS, 2017 ), ficando evidente que, além da falta de transparência e, consequentemente, descumprimento da lei, não há uma preocupação com a divulgação eficiente das informações, uma vez que, na maioria dos casos, são reveladas somente aquelas obrigatórias por lei.

A partir do momento em que o governo tem sua gestão baseada na transparência, colaboração e participação, viabilizam que o cidadão deixe de ser um sujeito passivo, ou seja, um mero consumidor de informaçôes e passe a ser coautor das políticas públicas, exercendo seu papel no processo democrático. Cabe aos gestores, principalmente dos municípios investigados, compreender que quando a sociedade participa das açóes e decisóes da administração pública, aumenta a legitimidade e a credibilidade do governo, além de auxiliar a responder às crescentes demandas públicas por informaçóes e serviços de melhor qualidade. A LAI, juntamente com o uso inteligente e político da internet, pode contribuir para mudanças significativas e positivas, desde que os gestores municipais cumpram com o papel de transformar a realidade atual (patrimonialista e pouco centrada no cidadão) 
em uma realidade baseada na transparência, colaboração e participação (BERNARDES; SANTOS; ROVER, 2015).

Nesta pesquisa, pode-se perceber que apesar de os municípios serem considerados de pequeno porte - diferentemente do estudo de Machado, Marques e Macagnan (2013) e Raupp e Pinho (2016) cujos municípios avaliados tem população superior a 50 mil habitantes e 300 mil habitantes, respectivamente - enfrentam muitas barreiras semelhantes às encontradas nos municípios considerados de grande porte. Essas barreiras ainda necessitam ser enfrentadas, principalmente a predominância da cultura do sigilo - mesmo que o caminho para a cultura da transparência esteja sendo trilhado. Os resultados deste estudo também permitem mostrar que, apesar do ingresso e consolidação das gestóes atuais, não houve mudanças significativas na transparência pública dos municípios do COREDE Missóes no período entre o estudo de Santos (2017) e esta pesquisa.

Isso leva a considerar que, de uma forma geral, boa parte dos municípios integrantes do COREDE Missóes têm muito a avançar para serem considerados de fato transparentes. Isso porque, os municípios que regulamentaram a LAI também necessitam de mudanças, pois em alguns, mesmo ratificando esta legislação, impossibilitam a interação entre cidadãos/ gestão pública nos seus portais eletrônicos.

A limitação encontrada para este estudo ocorreu em relação aos quatro municípios em que não foi possível efetivar o pedido de informação: Entre-Ijuís, Guarani das Missões, São Pedro do Butiá e Vitória das Missóes. A segunda limitação encontrada foi a não uniformização dos portais eletrônicos das prefeituras investigadas, bem como dos materiais por eles disponibilizados. A partir disso, para estudos futuros, recomenda-se um novo estudo nos municípios do COREDE Missóes, a fim de verificar as mudanças que ocorreram, assim como uma análise da EBT a nível estadual.

Através desta pesquisa, espera-se que os gestores públicos identifiquem as principais dificuldades da relaçáo entre cidadão/administraçáo pública no que diz respeito à participação popular na sua gestão, principalmente em relação aos portais eletrônicos. Sugere-se, portanto, como solução de cunho prático, a realização de audiências públicas como forma de incitar a participação da população aos assuntos de interesse sobre o município, pois a prática de tais eventos é dever dos gestores e direito dos cidadâos. Para que essas atividades sejam concretizadas, sugere-se a atualização, através de cursos ministrados gratuitamente pela Controladoria Geral da União (CGU) e pela Escola Virtual do Governo Federal, dos servidores e gestores públicos encarregados de atender à população no que se refere às transparências ativa e passiva dos municípios.

\section{REFERÊNCIAS}

ANGÉLICO, F. Lei de acesso à informação pública e seus possíveis desdobramentos à accountability democrática no Brasil. 2012. 133 f. Dissertação (Mestrado em Administração Pública e Governo) - Fundação Getúlio Vargas, Escola de Administração de Empresas, São Paulo, 2012. 
BALBE, R. D. S. Uso de tecnologias de informação e comunicação na gestão pública: exemplos no governo federal. Revista do Serviço Público, v. 61, n. 2, p. 189-209, 2010.

BERNARDES, M. B.; SANTOS, P. M.; ROVER, A. J. Ranking das prefeituras da região Sul do Brasil: uma avaliação a partir de critérios estabelecidos na Lei de Acesso à Informação. Revista de administração pública, v. 49, n. 3, p. 761-792, 2015.

BERTÊ, A. M. A.; LEMOS, B. O.; TESTA, G.; ZANELLA, M. A. R; OLIVEIRA, S. B. Perfil Socioeconômico - COREDE Missóes. Porto Alegre, n. 26, p. 518-554, fev. 2016.

BLANCHET, L. A.; AZOIA, V. T. A transparência na administração pública, o combate à corrupção e os impactos no desenvolvimento. Revista do Direito, v. 1, n. 51, p. 157-175, 2017.

BRASIL. Constituição (1988). Constituição da República Federativa do Brasil: promulgada em 5 de outubro de 1988.

BRASIL. LAI: A Lei de Acesso à Informaçáo. 2011. Lei n 12.527, de 18 de novembro de 2011. Presidência da República. Casa Civil. Subchefia para Assuntos Jurídicos. Brasília, 2011.

BROCCO, C. et al. Transparência da gestão pública municipal: Fatores explicativos do nível de transparência dos municípios de médio e grande porte do rio grande do sul.

Revista Ambiente Contabil, v. 10, n. 1, p. 139-159, 2018

BÜTTENBENDER, P. L.; SIEDENBERG, D. R.; ALLEBRANDT, S. L. Conselhos Regionais de Desenvolvimento (Coredes) RS: articulações regionais, referenciais estratégicos e consideraçôes críticas. DRd-Desenvolvimento Regional em Debate, v. 1, n. 1, p. 81-106, 2011.

CGU - Controladoria Geral da União. Escala Brasil Transparente. 2016.

COELHO, J. G. L.; FRIZZO, P. A.; MARCONDES, V. PRÓ-RS IV: Propostas estratégicas para o desenvolvimento regional do Estado do Rio Grande do Sul (20112014). Passo Fundo: Passografic, 2010.

CRUZ, C. F. et al.. Transparência da gestão pública municipal: um estudo a partir dos portais eletrônicos dos maiores municípios brasileiros. Revista de Administraçáo Pública, v. 46, n. 1, p. 153-176, 2012.

DALLABRIDA, V. R. A gestão social dos territórios nos processos de desenvolvimento territorial: uma aproximação conceitual. Sociedade, Contabilidade e Gestáo, v. 2, n. 2, p. 44-60, 2010. 
DA SILVA, C. L.; KUMEGAWA, L. S.; VASCONCELOS, M. C. Governo eletrônico e transparência: Comparativo entre as prefeituras municipais de Curitiba, Belo Horizonte, Salvador e Porto Alegre. Perspectivas Contemporâneas, v. 11, n. 3, p. 01-20, 2016.

\section{IBGE. INSTITUTO BRASILEIRO DE GEOGRAFIA E ESTATÍSTICA. IBGE}

Cidades, 2010. Disponível em: < https://cidades.ibge.gov.br/>. Acesso em: 05 abr. 2018.

JACQUES, F. V. S.; QUINTANA, A. C.; MACAGNAN, C. B. Transparência em municípios da região sul do Brasil. 2013. In: ENCONTRO NACIONAL DE ASSOCIAÇÃO NACIONAL DE PÓS-GRADUAÇÃO E PESQUISA EM ADMINISTRAÇÃO, 37., 2013, Rio de Janeiro. Anais eletrônicos... Rio de Janeiro, 2017.

JAMBEIRO, O.; SOBREIRA, R.; RABELO, P. TICs e gestão pública em planos diretores de cidades brasileiras. Revista Eptic, v. 11, n. 3, p. 01-23, 2009.

LACERDA, S. M. de P. Governo aberto, transparência e governo eletrônico nas câmaras municipais paraibanas: um estudo multicaso. 2016. 128 f. Dissertação (Mestrado em Administração) - Programa de Pós-Graduação em Administração, Universidade Federal da Paraíba, João Pessoa, 2016.

LIMA FILHO, N. et al.. Accountability e governo eletrônico: uma análise sobre a participação popular. Revista Pensamento Contemporâneo em Administraçáo, v. 5, n. 2, p. 17-32, 2011.

MACHADO, V. N.; MARQUES, S. B. S. S.; MACAGNAN, C. B. Nível de transparência por meio da evidenciação de informações obrigatórias de municípios do Rio Grande do Sul. ABCustos, v. 8, n. 3, 2013.

MEDEIROS, P. H. R.; GUIMARÃES, T. de A. A institucionalização do governo eletrônico no Brasil. Revista de Administração de Empresas, v. 46, n. 4, p. 1-13, 2006.

MICHENER, G.; MONCAU, L. F.; VELASCO, R. B. Estado brasileiro e transparência avaliando a aplicaçáo da Lei de Acesso à Informaçáo: relatório técnico. Rio de Janeiro: FGV, 2015, p. 108.

PAES, E. B. A construção da Lei de Acesso à Informação Pública no Brasil: desafios na implementação de seus princípios. Revista do serviço público, v. 62, n. 4, p. 407-423, 2014.

PIRES, A. M. Transparência da gestão pública municipal: um estudo dos municípios de Santa Maria e Novo Hamburgo/RS. 2013. 53f. Monografia (Especialização em Gestão Pública Municipal), Universidade Federal de Santa Maria, Santa Maria, 2013.

RAUPP, F. M.; PINHO, J. A. G. De. Construindo a accountability em portais eletrônicos de câmaras municipais: um estudo de caso em Santa Catarina. Cadernos EBAPE. v. 9, n. 1, p. 117-139, 2011. 
RAUPP, F. M.; PINHO, J. A. G. Review of passive transparency in Brazilian city councils. Revista de administraçáo, v. 51, n. 3, p. 288-298, 2016.

RAUPP, F. M. Realidade da transparência passiva em prefeituras dos maiores municípios brasileiros. Revista Contemporânea de Contabilidade, v. 13, n. 30, p. 34-52, 2016.

SANTOS, M. J. dos; CARNIELLO, M. F.; OlIVEIRA, E. A. A. Q. Comunicação digital na gestão pública dos municípios da RMVP: acesso à informação, transparência e mecanismos de participação. Revista Brasileira de Desenvolvimento Regional, Blumenau, v. 1, n .1, p. 167-184, 2013.

SANTOS, M. dos. Transparência na gestão pública Municipal nos Municípios que integram o Conselho Regional de Desenvolvimento das Missóes/RS. 2017. 180 f. Dissertação (Mestrado em Desenvolvimento e Políticas Públicas) - Curso de PósGraduação em Desenvolvimento e Políticas Públicas, Universidade Federal da Fronteira Sul, Cerro Largo, 2017.

SANTOS, M. dos; VISENTINI, M. S. Elaboração de um ranking da transparência e compreensão das práticas de gestão de municípios integrantes do COREDE Missões-RS. Administraçáo Pública e Gestáo Social, v. 10, n. 4, 2018.

SECRETARIA DO PLANEJAMENTO, MOBILIDADE E DESENVOLVIMENTO REGIONAL. Perfil Socioeconômico COREDE Missóes. Porto Alegre, 2015.

SILVA, T.; CRUZ, M. C. M. T; SPINELLI, M. V. A Transparência nos Governos Locais: o Cumprimento da Lei de Acesso à Informação pelas Controladorias Municipais Brasileiras. Encontro de Administraçáo Pública e Governança, VI, 2014.

SOARES, L. L. Transparência em Compras Públicas: proposta de um Índice da Transparência na Gestão de Compras Públicas Aplicado aos Websites de Municípios Brasileiros com mais de 100 mil habitantes. 168f. 2013. Dissertação (Mestrado em Ciências Contábeis). Universidade Federal de Santa Catarina, Florianópolis, Santa Catarina, 2013.

STAROSCKY, E. A et al. A transparência dos portais das prefeituras em municípios catarinenses sob a perspectiva da legislação brasileira. Reuna, Belo Horizonte, v. 19, n. 1, p. 29-52, 2014.

ZUCCOLOTTO, R.; TEIXEIRA, M. A. C.; RICCIO, E. L. Transparência: reposicionando o debate. Revista Contemporânea de Contabilidade, v. 12, n. 25, p. $137-158,2015$.

WBATUBA, B. B. R et al. Plano Estratégico de Desenvolvimento da Regiáo das Missóes/2015-2030, p. 320, Santo Ângelo: FuRI 2017. 